\section{Interferon $\alpha$ therapy in patients with chronic hepatitis C infection: quality of life and depression}

\author{
Ciro Conversano, ${ }^{1}$ Claudia Carmassi, ${ }^{1}$ \\ Marina Carlini, ${ }^{1}$ Giulia Casu, ${ }^{2}$ \\ Paola Gremigni, ${ }^{2}$ Liliana Dell'Osso' \\ 1Section of Psychiatry, Department \\ of Clinical and Experimental Medicine, \\ University of Pisa; ${ }^{2}$ Department of \\ Psychology, University of Bologna, Italy
}

\begin{abstract}
Health-related quality of life was examined in 49 patients with hepatitis $\mathrm{C}$ virus with no psychiatric history who received interferon (IFN)- $\alpha$ treatment. Quality of life was assessed at baseline, at 3 -time points during IFN- $\alpha$ therapy and at 1-6 month follow-up, using SF-36. Hepatitis C virus patients showed poorer physical functioning and better social and mental functioning than a normal population. Significant decreases from baseline SF36 scores were observed at an early phase of treatment. Six patients developed major depression during IFN- $\alpha$ treatment. At baseline, they had reported more bodily pain than patients who did not develop depression during treatment. Planned contrasts revealed that worsening in some dimensions of quality of life at 2 months was greater in depressed than in non-depressed patients. Results suggest that depressive symptoms should be accurately monitored during IFN- $\alpha$ therapy even in patients with no psychiatric history, especially if they present with bodily pain.
\end{abstract}

\section{Introduction}

Chronic hepatitis $\mathrm{C}$ infection (HCV) is associated with serious clinical sequelae, including hepatic fibrosis, cirrhosis of the liver, and hepatocellular carcinoma. ${ }^{1,2}$ Several studies also documented decreased levels of health related quality of life (HQOL) even in patients with compensated $\mathrm{HCV}$, compared to healthy controls. ${ }^{3-5}$

Pegylated interferon-alpha (IFN- $\alpha$ ) combined with ribavirin is the most effective pharmacological treatment for chronic hepatitis. It leads to sustained viral remission rates of $55 \%$, with the HCV genotype being the strongest predictor of outcome. ${ }^{6}$ However, IFN- $\alpha$, is associated with psychiatric adverse effects that also can worsen existing psychiatric conditions. ${ }^{7,8}$ In particular, either depression or depressive symptoms often emerge during IFN- $\alpha$ treatment, with more than $25 \%$ of patients under IFN- $\alpha$ therapy showing treatment-induced depression. ${ }^{9}$ These symptoms may significantly worsen HQOL. However, evidence of the impact of HCV and IFN- $\alpha$ treatment on HQOL is still unclear. Kang et al. reported impaired HQOL in patients with HCV. ${ }^{10} \mathrm{HQOL}$ decreased during early IFN treatment but significantly improved at 6-month follow-up. Chang et al. also observed that HCV patients under IFN therapy reported poor HQOL. ${ }^{11}$ Małyszczak et al. and Baranyi et al. found that 3 months after the first IFN- $\alpha$ administration, HQOL had significantly decreased in multiple domains. ${ }^{12,13}$ Pojoga et al. observed that the antiviral therapy does not affect the HQOL of HCV patients who have a markedly reduced HQOL both before and after treatment. ${ }^{14}$ On the other hand, Hunt et al. found neither a reduced HQOL in HCV patients compared with the general US population nor a change during IFN- $\alpha$ therapy. ${ }^{15}$ However, the incidence of depression significantly increased during the 6th month of IFN- $\alpha$ therapy. Differences in the results of studies could be partly accounted for by the variation in tools and inclusion criteria. With respect to the second aspect, most of the studies did not exclude patients with comorbid psychiatric and substance use disorders. These disorders have per se a strong negative impact on HQOL; hence, they may confound the relationship between HCV and HQOL. In order to eliminate the effects of co-occurring recent or past mental problems, in the present study we focused on perceived HQOL in a sample of HCV patients with no history of psychiatric and substance use disorders. We also examined the effect of depressive symptoms on HQOL during IFN- $\alpha$ therapy.

The objectives of the present study were: i) to compare the baseline HQOL of HCV patients with no history of psychiatric and substance use disorders with that of a normative sample; ii) to examine longitudinal changes in $\mathrm{HQOL}$ (baseline, during IFN- $\alpha$ treatment, and followup) of HCV patients, also taking into consideration possible differences between patients who developed depression during IFN- $\alpha$ treatment and those who did not.

\section{Materials and Methods}

\section{Study population}

Data were collected in the framework of a multicenter study aimed to investigate the course of HQOL and the possible emergence of psychiatric symptoms during IFN- $\alpha$ treatment, in HCV patients without lifetime history of any mental illness. ${ }^{16}$ Antiviral-naïve patients with chronic HCV (infected with genotype 1, 2, or 3
Correspondence: Claudia Carmassi, Department of Clinical and Experimental Medicine, University of Pisa, Via Roma 67, 56100 Pisa, Italy. Tel.: +39.050 .2219766 - Fax: +39.050 .2219787 .

E-mail: ccarmassi@gmail.com

Key words: depression, HCV, interferon, quality of life.

Contributions: $\mathrm{CC} 0, \mathrm{CCa}, \mathrm{MC}, \mathrm{LDO}$, data analyzing; $\mathrm{CC}$, $\mathrm{CCa}$, LDO, manuscript writing; $\mathrm{GC}$ and $\mathrm{PG}$, manuscript reviewing and references search.

Conflict of interests: the authors declare no potential conflict of interests.

Received for publication: 11 September 2014. Accepted for publication: 23 January 2015.

This work is licensed under a Creative Commons Attribution NonCommercial 3.0 License (CC BYNC 3.0).

(C) Copyright C. Conversano et al., 2015

Licensee PAGEPress, Italy

Hematology Reports 2015; 7:5632

doi:10.4081/hr.2015.5632

according to Simmonds' classification), of both genders, aged $\geq 18$ years, and with a liver biopsy providing histological diagnosis of active or persistent chronic hepatitis participated in the study. The following exclusion criteria were applied: current or lifetime psychiatric disorders (including alcohol or substance use disorders); previous treatment with IFN- $\alpha$ or other antiviral agents; pregnancy or breastfeeding; positivity for anti-human immunodeficiency virus, hepatitis B surface antigen, anti-hepatitis delta virus, autoimmune hepatitis, liver cirrhosis, metabolic liver diseases, and neoplastic diseases.

The study was designed before pegylated IFN was made available on the Italian market. Eligible patients were selected to receive IFN$\alpha$ plus ribavirin. The duration of treatment was 48 weeks for patients with genotype 1 and 24 weeks for patients with genotype 2 or 3 . Patients with genotype 1, who failed to show a virologic response after 6 months of therapy, were discontinued from treatment. All patients were assessed at baseline, monthly during the treatment period, and 1-6 months after the end of treatment. For the purpose of the present study, we analyzed data collected at 4 time points (baseline, 2, 4, and 6 months) during IFN- $\alpha$ treatment and at the follow-up visit. Forty-nine HCV patients participated in the study. Six of them developed depression during treatment (four patients at month 1, one patient at month 3 , and one patient at month 4). Of these, two dropped out because the severity of depression was not compatible with prosecution of IFN- $\alpha$ treatment. They were two males of 34 and 57 years who presented 
depression with panic symptoms after 3 and 4 months of treatment, respectively. They achieved complete clinical remission of depressive symptoms about 3 months after discontinuing IFN- $\alpha$ treatment. They were offered psychotropic drug treatment, but refused to take any other medication. The remaining four patients were treated with citalopram ( $20 \mathrm{mg} /$ day), achieved remission by the 5th month of treatment and completed the study. Three patients who did not develop depression also discontinued IFN- $\alpha$ treatment.

The Ethics Committee of the Azienda Ospedaliera Pisana (Pisa, Italy) approved the study procedures. All subjects entering the protocol provided written informed consent.

\section{Materials}

Psychiatric diagnostic assessment was conducted at baseline using the Structured Clinical Interview for DSMIV for Axis I DSM-IV Disorders, patient edition (SCID-I/P, version $2.0)$ to confirm the absence of any current or lifetime psychiatric disorders. ${ }^{17}$

Health-related QOL was assessed using the Italian version of the Medical Outcomes Study Short-Form 36 (SF-36)..$^{18}$ The SF-36 is a selfreport scale composed of 36 items, grouped into 4 physical health and 4 mental health domains. Physical health includes: physical functioning (PF; the extent to which health limits physical activities); role physical (RP; the extent to which physical health interferes with work or other daily activities); bodily pain (BP; the intensity of pain and impact on everyday work), and general health (GH; personal evaluation of health, current and perspective). Mental health includes: vitality (VI; feeling energetic), social functioning (SF; the extent to which physical health or emotional problems interfere with normal social activities), role emotional (RE; the extent to which emotional problems interfere with work or other daily activities), and mental health ( $\mathrm{MH}$; including anxiety, behavioral-emotional con-

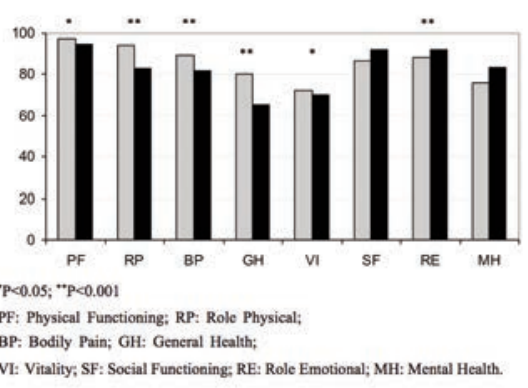

Figure 1. SF-36 scores in healthy norms (gray column) and patients with hepatitis C virus (black column). trol, general positive affect). Subscales raw scores are standardized and vary from 0 to 100 , where 0 implies the worst and 100 the best possible health status.

\section{Statistical analysis}

Scores at baseline were compared between the study sample and normative data using the one-sample $t$-test. The normative sample consisted of 608 healthy subjects drawn from the IQ0LA Study. 18

Repeated-measures ANOVAs with planned contrasts were performed on 5 consecutive measurements of SF-36 domains to test for within-group and between-group differences (depressed vs. non-depressed) over time. Planned contrasts were conducted to compare scores at each time point with the baseline. Type III sum of squares was used because of the unbalanced design. Statistical significance
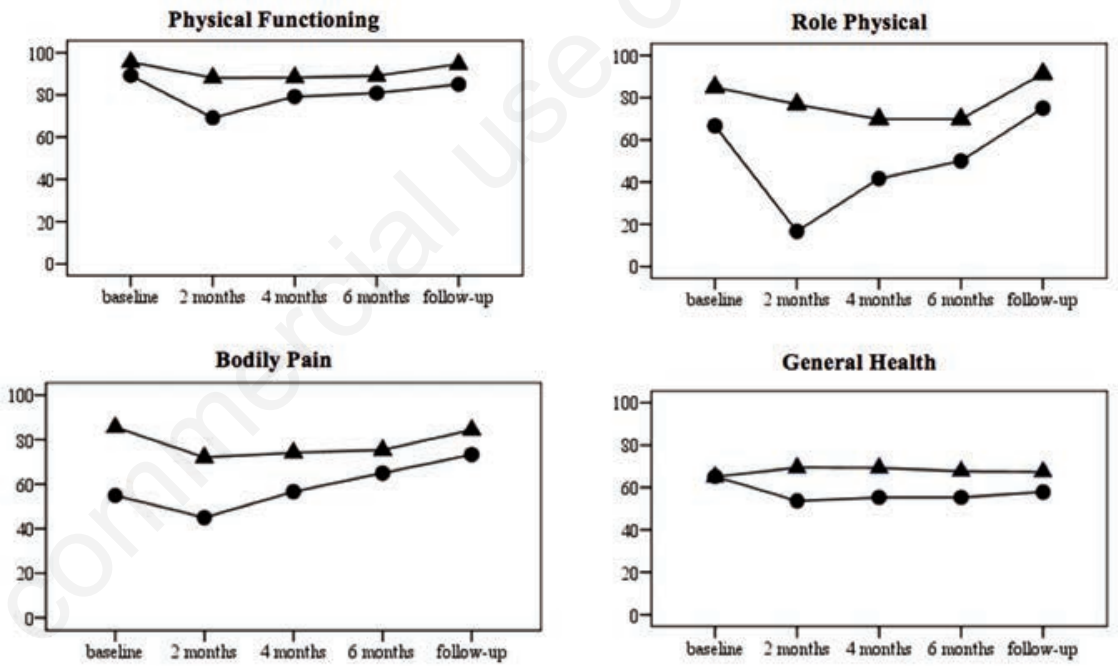

General Health
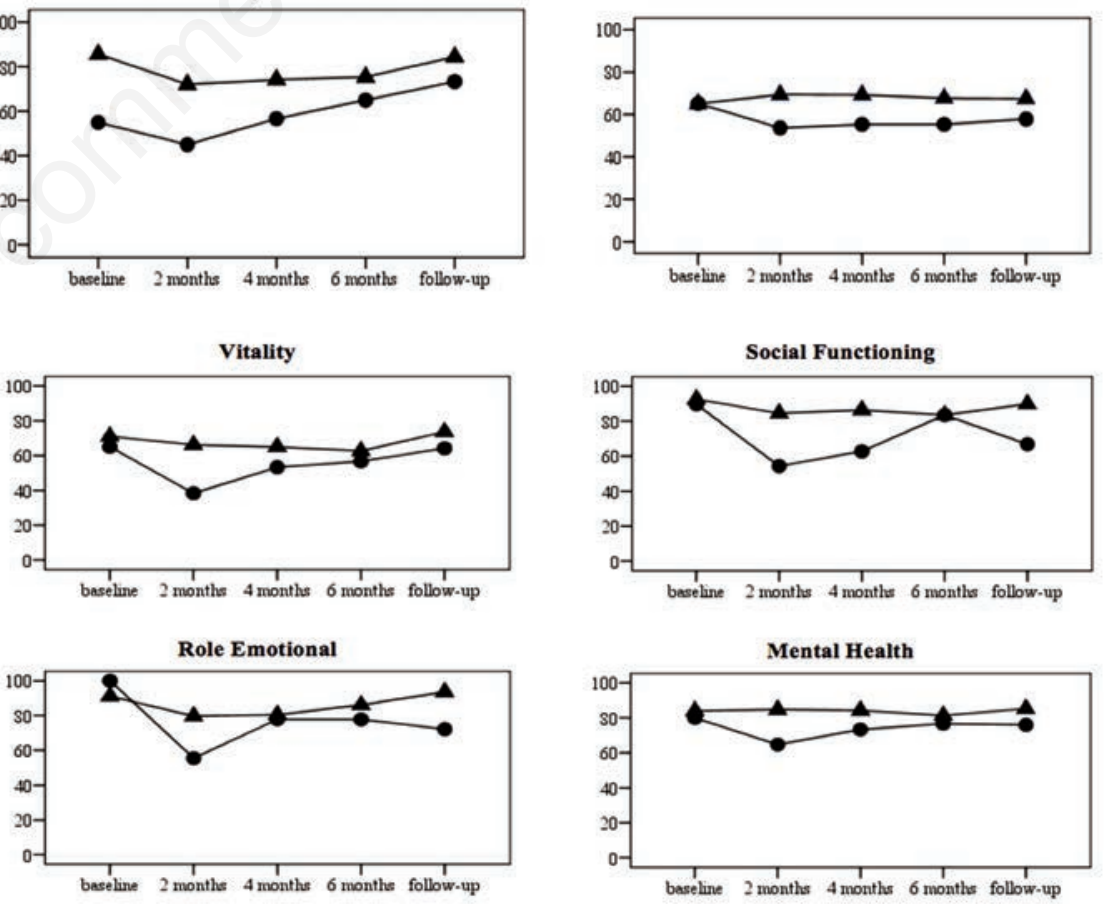

$\Delta$ nondepressed HCV-infected patients - depressed HCV-infected patients

Figure 2. SF-36 scores before, during and after interferon- $\alpha$ treatment in patients who developed depression and in those who did not. was established as P-values less than 0.05 , and Mauchly's test was significant.

\section{Results}

\section{Demographic characteristics sample}

The study sample included 49 patients with individuals developed depression during IFN- $\alpha$ treatment ( $50 \%$ females; mean age $48.3 \pm 10.5$ years). The normative group included 608 healthy individuals ( $46 \%$ females; mean age 34.8 years) drawn from the IQ0LA Study. ${ }^{18}$ 


\section{Comparison with healthy norms}

Compared with healthy norms, patients with HCV had significantly lower scores on $\mathrm{PF}$ $(\mathrm{t}=2.07, \mathrm{P}=0.04), \mathrm{RP}(\mathrm{t}=3.69, \mathrm{P}<0.001), \mathrm{BP}$ $(\mathrm{t}=2.69, \mathrm{P}<0.001)$, and $\mathrm{GH}(\mathrm{t}=7.81, \mathrm{P}<0.001)$, while they scored significantly higher on SF $(\mathrm{t}=-2.339, \quad \mathrm{P}=0.02)$ and $\mathrm{MH} \quad(\mathrm{t}=-3.41$, $\mathrm{P}<0.001$ ) (Figure 1).

\section{Longitudinal scores of the Italian version of the Medical Outcomes Study Short-Form 36}

Longitudinal scores on each SF-36 scale at baseline, at 3 time-points during treatment, and at the 1-6 month follow-up visit, are shown in Figure 2. At baseline, depressed patients had significantly lower scores on BP than nondepressed patients $(\mathrm{t}=3.93, \mathrm{P}<0.001)$.

Results of repeated-measures ANOVAs indicated main effects of both group and time for PF [time: $\mathrm{F}_{(4,188)}=6.64, \mathrm{P}<0.001$; group: $\mathrm{F}_{(1,47)}=4.67, \mathrm{P}=0.04$ ], RP [time: $\mathrm{F}_{(4,188)}=5.67$, $\mathrm{P}<0.001$; group: $\left.\mathrm{F}_{(1,47)}=6.12, \mathrm{P}=0.02\right]$, $\mathrm{BP}$ [time: $\quad \mathrm{F}_{(4,188)}=4.56, \quad \mathrm{P}=0.002 ; \quad$ group: $\mathrm{F}_{(1,47)}=7.164, \mathrm{P}=0.01$ ], VI [time: $\mathrm{F}_{(4,188)}=6.63$, $\mathrm{P}<0.001$; group: $\left.\mathrm{F}_{(1,47)}=3.99, \mathrm{P}=0.05\right]$, and $\mathrm{SF}$ [time: $\quad \mathrm{F}_{(4,188)}=6.88, \quad \mathrm{P}<0.001 ;$ group: $\left.\mathrm{F}_{(1,47)}=6.79, \mathrm{P}=0.01\right]$. There was also a significant interaction between group and time for $\mathrm{VI}$ $\left[\mathrm{F}_{(4,188)}=2.84, \quad \mathrm{P}=0.03\right] \quad$ and $\mathrm{SF}$ $\left[\mathrm{F}_{(3.17,148.86)}=4.56, \mathrm{P}=0.004\right]$.

Planned contrasts revealed that for both VI and SF, scores at 2 months decreased to a greater extent for depressed compared to nondepressed patients [VI: $\mathrm{F}_{(1,47)}=6.97, \mathrm{P}=0.01$; SF: $\mathrm{F}_{(1,47)}=5.9, \mathrm{P}=0.02$ ] indicating that $\mathrm{HCV}$ patients receiving IFN- $\alpha$ treatment show a greater decrease in these HQOL dimensions at an early phase of treatment. Nevertheless, SF scores at follow-up also were found to be significantly lower than at baseline in depressed compared to non-depressed patients $\left[\mathrm{F}_{(1,47)}=4.75, \mathrm{P}=0.03\right]$. RE decreased over time with no effect of group [time: $\mathrm{F}_{(4,188)}=3.4$, $\mathrm{P}=0.03$; group: $\mathrm{F}_{(1,47)}=1.22, \mathrm{P}>0.05$ ], while $\mathrm{MH}$ showed no change over time and a main effect of group [time: $\mathrm{F}_{(4,188)}=2.08, \mathrm{P}>0.05$; group: $\left.\mathrm{F}_{(1,47)}=4.46, \mathrm{P}=0.04\right]$. However, for $\mathrm{MH}$ there was a significant interaction between time and group $\left[\mathrm{F}_{(4,188)}=2.93, \quad \mathrm{P}=0.02\right]$. Contrasts showed that MH scores at 2 months decreased to a greater extent for depressed compared to non-depressed patients $\left[\mathrm{F}_{(1,47)}=8.16\right.$, $\mathrm{P}=0.006$ ], indicating that HCV patients with INF-induced depression show a greater reduction in mental health at an early phase of treatment only.

No significant main effects of time or group or a group per time interaction were found for GH [time: $\mathrm{F}_{(4,188)}=0.37, \mathrm{P}>0.05$; group: $\mathrm{F}_{(1,47)}=2.31, \quad \mathrm{P}>0.05$; time per group: $\left.\mathrm{F}_{(4,188)}=1.66, \mathrm{P}>0.05\right]$, indicating that $\mathrm{GH}$ remains stable during IFN- $\alpha$ treatment in both depressed and non-depressed patients.

In summary, HCV-infected patients with no history of psychiatric diseases showed significant decreases in some of HQOL domains during IFN- $\alpha$ treatment, and this effect was accentuated in patients who developed major depression during treatment.

\section{Discussion and Conclusions}

In the present study, we found significant differences in SF-36 HQOL scores between HCV patients without history of psychiatric and substance use disorders and healthy norms. Specifically, patients with HCV had lower scores than norms on physical functioning, role physical, bodily pain, and general health. Our results are in part similar to those of previous studies. ${ }^{3-5}$ Moreover, in our study, patients with HCV had higher scores than healthy norms on SF and MH. Such results differ from those of other authors who reported decreased levels on SF and MH in HCV patients compared to the general population. ${ }^{10,14}$ Our findings may be partly explained by the exclusion criteria that eliminated from our study all patients with comorbid lifetime psychiatric and substance use disorders. In support to this explanation, Hollander et al. found that prior intravenous drug users (IVDUs) scored significantly lower on SF $(\mathrm{P}=0.03)$ and $\mathrm{MH}(\mathrm{P}=0.03)$ than patients who had acquired their infection from blood transfusions. ${ }^{19}$

Considering the whole sample of our study, during IFN- $\alpha$ treatment most of the SF-36 domains decreased, with the exception of general and mental health scores. Such results differ from those of Hunt et al. who found that patients with HCV exhibited health perceptions similar to those of the general US population that remain unchanged during IFN- $\alpha$ therapy. ${ }^{15}$

After starting IFN- $\alpha, 12.5 \%$ of our study participants developed major depression. These patients had significantly lower scores on BP at baseline than patients who did not develop depression. The effect of IFN-induced depression on HQOL increased at the 2-month assessment. Specifically, patients who became depressed were more seriously impaired in energy, social functioning and mental health than those who did not develop depression. On average, depressed patients had lower scores on all SF-36 scales, except role emotional and general health, when compared with nondepressed patients.

On the basis of our findings, we can conclude that IFN- $\alpha$ may induce depression even in subjects without a psychiatric and substance use disorder history. In addition, bodily pain at baseline seems to be associated with development of depression during treatment.
Consequently, our results suggest that depressive symptoms should be accurately monitored during IFN- $\alpha$ treatment even in subjects with no history of psychiatric and substance use disorders. A particular attention should be placed in patients who report decreased levels of HQOL and bodily pain before entering the treatment.

The reduced sample size of this study, partly due to the strict exclusion criteria used, may have allowed significant associations to go undetected and may, therefore, limit the generalizability of our results.

\section{References}

1. Pockros PJ. Developments in the treatment of chronic hepatitis C. Expert Opin Investig Drugs 2002;11:515-28.

2. Strader DB, Wright T, Thomas DL, Seeff LB. American Association for the Study of Liver Diseases. Diagnosis, management, and treatment of hepatitis C. Hepatology 2004;39:1147-71.

3. Rowan PJ, Al-Jurdi R, Tavakoli-Tabasi S, et al. Physical and psychosocial contributors to quality of life in veterans with hepatitis C not on antiviral therapy. J Clin Gastroenterol 2005;39:731-6.

4. Spiegel BM, Younossi ZM, Hays RD, et al. Impact of hepatitis $\mathrm{C}$ on health related quality of life: a systematic review and quantitative assessment. Hepatology 2005;41:790-800.

5. Taliani G, Rucci P, Biliotti E, et al. Therapy expectations and physical comorbidity affect quality of life in chronic hepatitis $\mathrm{C}$ virus infection. J Vir Hep 2007;14:875-82.

6. Shepherd J, Brodin HF, Cave CB, et al. Clinical- and cost-effectiveness of pegylated interferon alfa in the treatment of chronic hepatitis C: a systematic review and economic evaluation. Int $\mathrm{J}$ Tech Assess Health Care 2005;21:47-54.

7. Quelhas R, Lopes A. Psychiatric problems in patients infected with hepatitis $\mathrm{C}$ before and during antiviral treatment with interferon-alpha: a review. J Psychiatr Pract 2009;15:262-81.

8. Horsmans Y. Interferon-induced depression in chronic hepatitis C. J Antimicrob Chemother 2006;58:711-3.

9. Keefe B. Interferon-induced depression in hepatitis C: an update. Curr Psychiatry Rep 2007;9:255-61.

10. Kang SC, Hwang SJ, Lee SH, et al. Healthrelated quality of life and impact of antiviral treatment in Chinese patients with chronic hepatitis $\mathrm{C}$ in Taiwan. World $\mathrm{J}$ Gastroenterol 2005;11:7494-8.

11. Chang SC, Ko WS, Wu SS, et al. Factors associated with quality of life in chronic 
hepatitis $\mathrm{C}$ patients who received interferon plus ribavirin therapy. J Formos Med Assoc 2008;107:454-62.

12. Małyszczak K, Inglot M, Pawłowski T, et al. Depressive symptoms during treatment with interferon alpha for HCV infectionpreliminary report. Psychiatr Pol 2006;40:799-808.

13. Baranyi A, Meinitzer A, Stepan A, et al. [Interferon therapy in patients with chronic hepatitis C infection: Biopsychosocial consequences]. Nervenarzt 2011;83:1169-77. [Article in German].

14. Pojoga C, Dumitra cu DL, Pascu 0,
Grigorescu M. The effect of interferon alpha plus ribavirin on health-related quality of life in chronic $\mathrm{C}$ hepatitis. The Romanian experience. J Gastrointestin Liver Dis 2006;15:31-5.

15. Hunt CM, Dominitz JA, Bute BP, et al. Effect of interferon-alpha treatment of chronic hepatitis $\mathrm{C}$ on health-related quality of life. Dig Dis Sci 1997;42:2482-6.

16. Dell'Osso L, Pini S, Maggi L, et al. Subthreshold mania as predictor of depression during interferon treatment in $\mathrm{HCV}+$ patients without current or lifetime psychiatric disorders. J Psychosom Res 2007;62:349-55.
17. First MB, Spitzer RL, Williams JBW, Gibbon M. Structured clinical interview for DSM-IV-patient edition (SCID-P). Washington, DC: American Psychiatric Press; 1995.

18. Apolone G, Mosconi P, Ware JE Jr. Questionario sullo stato di salute SF-36. Milan: Guerini e Associati Spa; 1997.

19. Hollander A, Foster GR, Weiland O. Healthrelated quality of life before, during and after combination therapy with interferon and ribavirin in unselected Swedish patients with chronic hepatitis C. Scand J Gastroenterol 2006;41:577-85. 